\title{
Analysis on the Development of Chinese Agricultural Machinery
}

\author{
Hao Zhang ${ }^{\mathrm{a}}$, Shuchao $\mathrm{Li}^{\mathrm{b}}$ \\ School of economics and management, Qingdao agricultural University, Qingdao 266109, China \\ azhxfs@163.com, 'Isc@qau.edu.cn
}

Keywords: Agricultural machinery; Development; Technology.

\begin{abstract}
To realize the four modernizations of industry, agriculture, science and technology, and defense is the goal of China's socialist construction, as the basic industry, agriculture plays an important role in the national economic development. Agricultural mechanization is the main direction of China's agricultural development, mechanized production can save workforce, labor time; however, only some parts of China have currently implemented agricultural mechanization, most areas are still traditional farming agriculture, so it is urgent to accelerate the reform of agricultural machinery research and development and to improve agricultural mechanization in China. This paper describes the main issues in the development of China's agricultural machinery, noting the direction of China's agricultural development; analyzing the development trend of modern agricultural machinery so as to promote the modernization of China's agricultural machinery development.
\end{abstract}

\section{An agricultural machinery development status and characteristics}

From the analysis of a series of major positive policy issued in recent years, market demand trends and other product trends and cost tendency, in 2014, China agricultural machinery industry will continue to maintain a sustained, steady, rapid and coordinated development of situation(Figure 1).

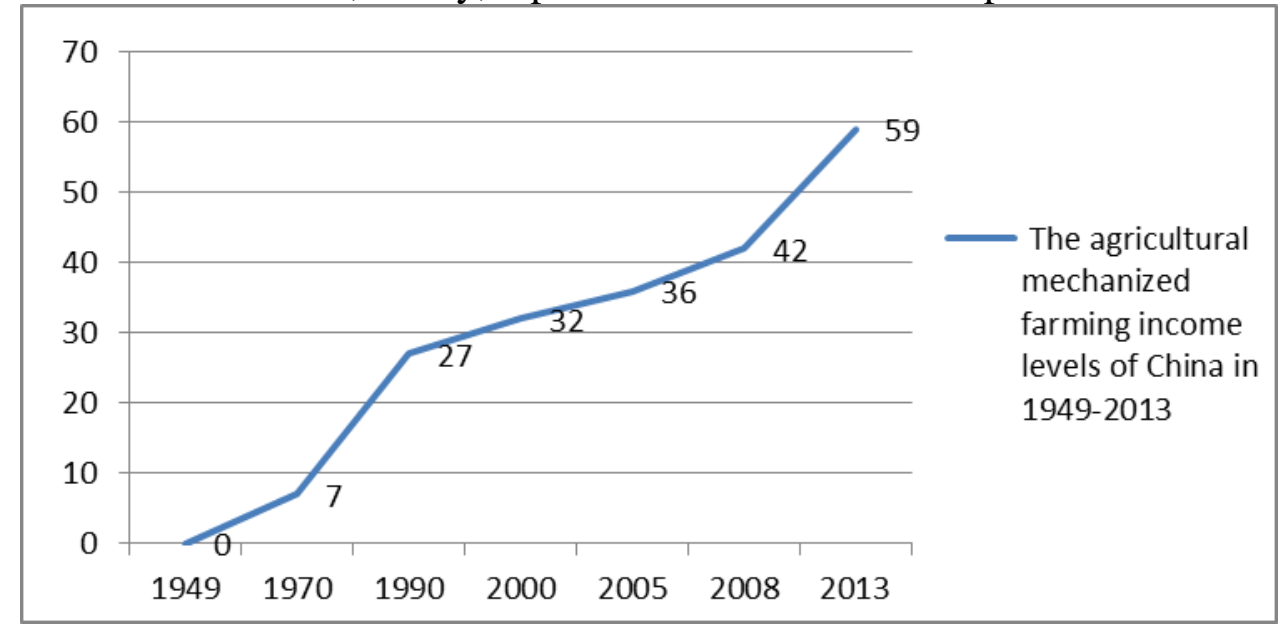

Fig.1 The agricultural mechanized farming income levels of China in 1949-2013

The main features of China's agricultural machinery development include: the demand increases year by year, agricultural product categories increase, social development pattern of gradual, market-oriented services. With the continuous development of technology and economy, the current level of farming mechanization of China has reached one third, and the total power increased to 8.4 billion KW. On the other hand, the adjustment of industrial structure in rural areas promotes the diversification of agricultural products; machines of pasture, forestry, and industrial crop gradually replace the traditional agricultural machinery products, becoming a direction of selection of agricultural machinery product preferences. Taking the development of a variety of economies as an opportunity, responding to large-scale production of machinery products, such as the demand for lifting equipment, excavators and loaders and other products is also growing. Meanwhile, restrictions on land size in China prompted farm machinery socialization services as the major elements of today's small farmer household's mechanization of production. According to statistics, by 
trans-regional operation, the utilization of combine-harvesters increases from about a week to a month or so every year.

Table 1 The United States, Japan, China agricultural machinery development

\begin{tabular}{|c|c|c|c|c|c|c|}
\hline countries & period & \multicolumn{3}{|c|}{ phases } & \multicolumn{2}{|c|}{ characteristic } \\
\hline & 1910-1975 year & \multicolumn{3}{|c|}{ Mechanized phase } & \multicolumn{2}{|c|}{$\begin{array}{r}\text { From half mechanization for } n \\
\text { development stage gra }\end{array}$} \\
\hline \multicolumn{7}{|l|}{ America } \\
\hline & Since 1975year & \multicolumn{3}{|c|}{$\begin{array}{l}\text { Intelligent, automation } \\
\text { development stage }\end{array}$} & \multicolumn{2}{|c|}{$\begin{array}{l}\text { Intelligent, automated mac } \\
\text { become the new main }\end{array}$} \\
\hline & 1947-1984 year & \multicolumn{3}{|c|}{$\begin{array}{c}\text { From the early stage to In-depth } \\
\text { development stage }\end{array}$} & \multicolumn{2}{|c|}{$\begin{array}{r}\text { Agricultural mechanization c } \\
\text { step by step }\end{array}$} \\
\hline \multicolumn{7}{|l|}{ Japan } \\
\hline & Since 1985year & \multicolumn{3}{|c|}{ Diversified development stage } & \multicolumn{2}{|c|}{ Present diversified agricultur } \\
\hline \multirow{2}{*}{ China } & 1996-2003 year & \multicolumn{3}{|c|}{ Market development phase } & \multicolumn{2}{|c|}{$\begin{array}{c}\text { Under the economic develop } \\
\text { agricultural economy mark } \\
\text { obvious }\end{array}$} \\
\hline & Since 2004year & \multicolumn{3}{|c|}{ Deepening the development stage } & \multicolumn{2}{|c|}{$\begin{array}{l}\text { Secured by the rapid devel } \\
\text { national policy }\end{array}$} \\
\hline \multicolumn{7}{|c|}{$\begin{array}{l}\text { As we can see from table } 1 \text {, the United States and Japan use of agricultural machinery } \\
\text { management experience, since 2004, the rapid development of China's agricultural } \\
\text { under the protection of national policy, but less prominent contradictions basis }{ }^{[1]} \text {. } \\
\text { Table } 2 \text { China, the United States and Canada compare the cost of production of major } \\
\text { products }\end{array}$} \\
\hline & \multicolumn{6}{|c|}{ Cost structure } \\
\hline & Variety & country & Labor & machinery & fertilizer & Land \\
\hline & \multirow{2}{*}{ Paddy } & China & 42 & 13 & 22 & 0 \\
\hline & & U.S. & 9 & 26 & 17 & 19 \\
\hline & \multirow{3}{*}{ Wheat } & China & 35 & 17 & 22 & 0 \\
\hline & & U.S. & 9 & 21 & 24 & 12 \\
\hline & & Canada & 9 & 28 & 37 & 3 \\
\hline & \multirow{2}{*}{ Corn } & China & 46 & 11 & 23 & 0 \\
\hline & & U.S. & 9 & 29 & 20 & 24 \\
\hline & \multirow{2}{*}{ Soybean } & China & 46 & 11 & 11 & 0 \\
\hline & & U.S. & 8 & 27 & 14 & 31 \\
\hline & \multirow{2}{*}{ Rapeseed } & China & 55 & 7 & 18 & 0 \\
\hline & & Canada & 9 & 28 & 37 & 3 \\
\hline
\end{tabular}

As can be seen from the table 2, our agricultural production costs higher than in other countries is mainly due to the proportion of the labor force is too high, a lower proportion of machinery costs possession. So if China's agricultural production and a substantial increase if the level of mechanization and automation, will certainly increase agricultural productivity, to reduce farm costs.

\section{Development situation of agricultural mechanization}

Less investment Page Numbers. Farmers are the subject of the rural economy, and rural economic is lagging behind, although China has adopted a lot of related policies to help resolve issues of agriculture, but this is utterly inadequate for the majority of farmers as it is impossible to completely cover all Chinese farmers. Therefore, to a large extent farmer's income and expenses are not in proportion, many farmers do not have the economic capacity to purchase agricultural machinery, only relying on traditional human cultivation. Farmers are the main part of agricultural mechanization investment, but rural economic development is lagging behind in relative terms. Although China has adopted a series of "three rural" policies, which has a positive meaning for optimizing agricultural configuration, only like a drop in the bucket, the improvement of rural 
economy contrasting with the speed of urbanization and the development of market-oriented process, its relative backwardness is difficult to change, so that the income of farmers is in great imbalance.

Land restrictions. China's per capita land area is very small, and is now showing a decreasing trend. At present, China's land quality is declining, soil erosion, desertification, causing the gradual reduction in arable fields. The overall quality of China's land resources is gradually reducing, land degradation and desertification become killers of some agricultural land, for example, the abandoned land area in Inner Mongolia region nearly reached 40,000 hm2 [2]. land is used for other non-agricultural uses, some cultivated land resources are increasingly reducing, and most farmers follow a traditional family-contract responsibility system, based population land is divided into fragmented blocks, it is difficult to integrate different places, different terrain of the land together to carry out mechanized farming, for most non-plain areas traditional farming methods are still widely used, agricultural extension in these areas is rather difficult [3].

Less technology investment. China's terrain is rather complex, agricultural machinery is currently available only in the plains, but in the vast mountainous area also has agricultural land, because of less technology investment so there is no development of agricultural machinery in the region, leading to farmers in the region still follow the traditional farming. Currently, subject to economic development, China's investment for agricultural research is not enough. Attaches great importance to the current revision of the standard, perfecting standard system, so as to adapt to the development of technology and demand [4].Some flaws technical reserves, aging and lagging research scientific instruments, are the portrayal of Chinese agricultural research, these potential problems and needs of agricultural scientific and technological revolution is detached, and the machine made by lagging research, its mechanical life species relative to some foreign country with advanced productive forces is obviously insufficient, the number of large and medium tractors is small, farm machinery and equipment structure loss of rationality, then make agricultural growth in the presence of large number of variables, the overall performance of agricultural products can't keep up with production development.

\section{Development direction of automation, intelligent of Chinese agricultural production}

Application CAD technology. The application of two-dimensional interactive graphics software in agricultural enterprises is relatively common. With PTC's Pro / E as the representative of parametric design and feature-based design of three-dimensional solid modeling design software has been started in some Chinese agricultural enterprises. CAD / CAE / CAM technology has begun to use a small number of agricultural enterprises, mainly some good CAD-based enterprises in the three-dimensional CAD (such as Pro / E, MDT), based on the use of third-party products such as Ansys (finite element analysis and optimization software), Edge CAM (pass trajectory generation software), etc., engineering analysis and aided manufacturing, complex surface parts of some large agricultural machinery and precision requirements were CAD / CAM / CAE technology applications. Meanwhile, the Chinese farm workers in customization and secondary development of foreign CAD / CAM / CAE software, has also done a lot of work.

Application of Hydraulic Technology. In recent years, vehicles and agricultural machinery hydraulic technology is mainly relying on the application of microelectronics technology, industrial sensor technology, computer real-time control and modern control theory and methods. Because of the efficiency of modern hydraulic components nearly limit, vehicles and agricultural machinery multi-use internal combustion engine as the prime mover, the workload changes frequently, large amplitude. The main way to improve the efficiency of the system is to achieve the best match between the load and the prime mover by means of electro-hydraulic control, and to reduce power transmission losses as much as possible. Using variable differential pressure control pumps and top load based adaptive system has been widely adopted. Electro-hydraulic drive system real-time control of computer and sensor technology and microelectronics technology combines mechanical prime mover has been able to achieve the best match and load control, when the load changes make 
the prime mover to work in the best efficiency zone, and the former motivation and drive system to implement real-time monitoring.

Application of intelligent electronic technology. Electronic information technology and intelligent technology in agricultural machinery and equipment in promoting support for "precision agriculture" intelligent variable operating machinery application of information and knowledge-based research and development. Technical innovation of electronic information technology and intelligent machinery and equipment used in agriculture are in five areas. Tractors and self-propelled agricultural machinery electronic forward networked, intelligent, distributed control technology direction. Large tractors and agricultural machinery has been installed by a complex of several standard electronic control unit (ECU), actually is a computer intelligent independent processing information and control functions with a control terminal for universal micro agricultural machinery specially designed environment computer operations, and have a unified standard design interface, using the control Area Network (abbreviated CAN) technology and network communication protocols.

Application of Computer Vision Technology. Computer vision is developed on the basis of image processing on emerging science, research information from the cognitive processes of information processing level, the study of visual information processing theory of computation, expression and calculation methods. On the characterization and classification of agricultural products is the use of computer vision techniques nondestructive testing, it can be measured without contact to obtain specific information from the surface of the image of agricultural products, agricultural products and thus quality assessment and classification. The computer vision technology to produce a comprehensive testing and quality assessment has incomparable superiority. Compared with manual inspection, non-destructive testing using computer vision technology with high efficiency, high recognition rate, the advantages of a unified standard.

\section{Chinese agricultural machinery development strategies}

Agricultural machinery technology innovation to create favorable conditions. China Agricultural Technology Innovation Square and the associated facilities is not perfect, around the farm power, harvesting machinery and other fields, should establish a number of relatively independent national key laboratories and other infrastructure sectors in the public technology platform to support innovative agricultural machinery development, through the establishment of special operations for technical innovation funds to support continued innovation of agricultural science and technology industry significant problems.

Adhere to the development strategy of going out. Development and cooperation is strong and effective enterprise development cannot be confined to the development of agricultural enterprises in the domestic market but also from the introduction of foreign advanced technology and advanced agricultural enterprises to enhance strategic cooperation in order to achieve the overall level of innovation of agricultural machinery industry, such as China is currently in intensive production areas of agricultural technology, efficient use of resources in the field of agricultural technology based on clean energy technologies and research areas such party is not enough, you also need to find the gap from the introduction of technology, and innovation. Meanwhile China many advanced agricultural machinery should also insist on the idea of going out, emancipating the mind and seeking truth from facts, for achievements in the field of agricultural and strength of their own brands.

Sound technology innovation policy support, tax incentives to help establish a sound system of the development of agricultural machinery industry. Through tax regulation, encourage and guide enterprises to increase agricultural machinery for technical innovation and research inputs and increase agricultural machinery new technology and new product promotion and subsidies, at the policy level to support innovation and development of agricultural machinery. Attention to the development of agriculture to adapt to sustainable development, can effectively protect the agricultural ecological environment and achieve efficient utilization of agricultural resources, agricultural machinery, such as ecological agriculture, conservation tillage minimum tillage, 
no-tillage joint operating machinery, organic fertilizer, slow-release fertilizer, and efficient toxic pesticide production and administration machinery, agricultural waste in the production process, such as straw and stubble crops, livestock intensive rearing of livestock manure and wastewater, agricultural product processing and comprehensive utilization of waste and other waste harmless processing equipment, such as development priorities.

Chinese should emphasize on high-tech application in agricultural products and promotion, and enhance high-tech agricultural products. The wide application of computers, microelectronics, automation, intelligence and other high-tech mechanical and electronic integration on agricultural equipment brings out a "precision agriculture", which greatly improves the level of agricultural production, at the same time, greatly improves the operating performance of agricultural machinery. In order to meet the development of modern agriculture in our country, the demand around the establishment of a modern agricultural system, with emphasis on the development of areas of modern agricultural machinery as shown[5]:

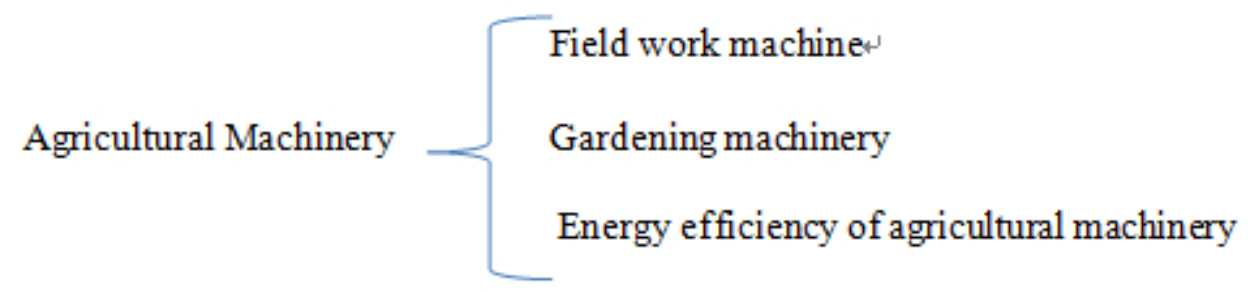

Fig.2 Key development areas of agricultural machinery

\section{Conclusion}

Agriculture in the adjustment of industrial structure and to meet social and economic needs of the market and gradually developed into an indispensable component of the modern era of science and technology is highly developed, as the development of agricultural machinery agricultural machinery idea is to make science and technology with the benefits of technology to achieve unity and a higher level of integration. Although China's development of agricultural machinery is still in the process of trial and error, but if the mechanical process of development, research-premise technical innovation, training of agricultural professionals, as well as the integration of policy support, can be limited from more among the quality so that a more steady development of agricultural mechanization.

\section{References}

[1] Q.J. Li: World Agriculture, Vol. 408 (2013) No.4, p.91.

[2] H.X. Wang: Farming technical consultant, Vol.01 (2011).

[3] Z.P. Mo: Technology wind, Vol.17 (2011).

[4] X.S Zhang and J.B Chen: Focus, (2008) No.7, p.13.

[5] G. Yang: Agricultural science \& technology and equipment, Vol. 228 (1994) No.6, p.101. 